\title{
Assess the Level of Knowledge and Practice among mothers of Pre-school Children about Worm Infestataion and Effectiveness of Innovative Health Counseling
}

\author{
*Ms.GnamaniP , **Dr.Kamalam $S$ \& ***Mr.Ramaprabhu $Z$
}

\section{Abstract:}

Objectives- To evaluate the effectiveness of innovative health counselling among mothers of pre-school children about worm infestation. Method- A quasi experimental design was adopted for the study. Result-.The mothers of pre-school children have gained adequate knowledge on worm infestation where the post-test Mean was (2.72) SD (0.451) when compared to pre-test which had a mean of (1.44) SD (0.641).which was statically significant at $P<0.000$ Conclusion-.It describes that the mothers of pre-school children have gained adequate knowledge on worm infestation which proved that the innovative health counselling programme was highly effective among the mothers of pre-school children.

Keywords: Innovative health counselling, Worm-infestation.

\section{INTRODUCTION}

Prevention is the key step but early intervention can improve the outcome. Positive hygienic practices are essential for the treatment of worm infestation.

Today's world is highly advanced by means of technology, people live in a modernized and scientifically improved world, which influences the life of every individual $^{1}$. Hence, the people living in urban areas have high socio economic status than people of rural areas. So rural people lack their needs, thus it leads to unhygienic practices.

Worm infestation is widely prevalent in India Necatoramericanus is predominant in South India and Ancylostomaduodenale in North India². Recently another species A. ceylanicum has been reported from a village near Kolkata4.
Most of mothers in rural areas as evidenced in the study conducted at Pondicherry (1992) revealed unawareness towards hygienic measures which in turn leads to many helminthic infection to children ${ }^{3}$.

\section{OBJECTIVES:}

1. To assess the level of knowledge and practice on worm infestation among mothers of pre-school children.

2. To evaluate the effectiveness of innovative health counseling on knowledge \& practice among mothers of pre-school children about worm infestation

3. To associate the level of knowledge and practice among mothers of pre-school children about worm-infestation with the selected demographic variables. 


\section{HYPOTHESES:}

H1 - The post test knowledge score will be significantly higher than the pre-test knowledge score on worm - infestation among mothers of pre-school children.

\section{METHODOLOGY}

The conceptual frame work of the present study was based on Rosen stock's Health belief Model. A quasi experimental design was used in this study, 100 mothers of pre-school children from PCP nagar, Ariyankuppam were selected by using purposive sampling method. Totally 100 mothers of pre-school children were selected for the study. Data collection was done by using semi-structured interview questionnaire which consisted of 30 questions related to demographic data, and questions related to worm infestation were set to assess the knowledge and practice of the mothers of pre-school children.

\section{Sampling Criteria:}

\section{Inclusion Criteria}

- Mothers of children (3-6yrs) of age who are having child.

- Mothers giving consent for the study.

- Mothers living in rural areas.

\section{Exclusion Criteria}

- Mothers who are not giving consent.

- Mothers living in urban areas.

- Mothers who are not having under five children.

Setting of the study:

The study was conducted in Ariyankuppam, Pudhucherry.

\section{Tool Construction:}

PART-I Demographic variable.

PART-II structured questionnaire for knowledge.

PART-III: structured questionnaire for practice.

\section{Data collection procedure:}

Prior to actual data collection, the population of pcpnagar was noted from Ariyankuppam primary health centre records then attempts were made to build rapport with the mothers in pcpnagar, thereafter data collection was carried out. The purpose of the interview was explained to all the mothers with self-introduction. Nearly 45 minutes were spent to conduct the study for seven subjects

\section{RESULT}

The result reveals that the mothers of pre-school children have gained adequate knowledge on worm infestation where the post-test Mean was (2.72) SD (0.451) when compared to pretest which had a MEAN (1.44) SD (0.641)and is statistically significant ( $p$ value $<0.000$ ) which proved that the innovative health counseling programme was highly effective among the mothers of pre-school children. Hence, information education and communication activities play an important role in creating awareness on worm infestation among the mothers which is most important for the pre-schoolers because worm infestation is one of the reason for the child being malnourished and getting anaemia.

\section{CONCLUSION}

There was a significant association between the level of practice and age of the mother at $\mathrm{P}<0.05$ level.

\section{REFERENCES:}

1. Utzineger J,(2008) A new sensitive technique for the diagnosis of hook worm infections in humans. Public Health and Epidemiology .

2. Goodman D, (2007) A comprasion of methods for detecting the eggs of Ascaris,Trichuris, and hookworm in infant stool and in epidemiology of infection in Zanzibari infants. American Journal of Medicine.

3. Ananthanarayanan .Text book of microbiology (4 ${ }^{\mathrm{TH}}$ edition) Madras Orient Longman

4. BasavanthappaCommunty Health Nursing (1 ${ }^{\text {ST }}$ edition ) New Delhi JAYPEE BROTHERS MEDICAL PUBLISHERS

(P) Ltd.28. 